\title{
Skeletal mineralisation during long bone growth in young horses
}

\author{
F.M.D. Henson, M.E. Davies* and L.B. Jeffcott \\ Department of Clinical Veterinary Medicine, University of Cambridge \\ * Strangeways Research Laboratory, Cambridge
}

\begin{abstract}
Summary
The cartilage changes occurring during skeletal mineralisation in young horses were investigated by histological, ultrastructural, histochemi$\mathrm{cal}$, in situ hybridisation and immunolocalisation techniques. Alkaline phosphatase was detected in the proliferative and hypertrophic zones of growth cartilage. Uitrastructurally alkaline phosphatase was seen on cell surface membranes and concentrated into matrix vesicles, the putative sites of mineralisation within cartilage. Type $X$ collagen was only detected associated with the terminally differentiated hypertrophic chondrocytes adjacent to the newly forming subchondral bone.
\end{abstract}

keywords: mineralisation, cartilage, alkaline phosphatase, collagen

\begin{abstract}
Mineralisierung des Skeletts während des Wachstums der langen Gliedmaßenknochen bei jungen Pferden
Mit Hilfe von histologischen, elektronenoptischen und histochemischen Methoden ebenso wie durch in situ Hybridisation und immunologische Techniken wurde die Knorpelentwicklung während der Mineralisation des Skelettes bei Fohlen untersucht.

In den proliferativen und hypertrophen Zonen des Wachstumsknorpels kommt die alkalische Phosphatase vor. Nach dem elektronenoptischen Bild liegt sie an den Membranen der Zelloberfläche, besonders konzentriert aber in den Matrixvesikein, dem vermutlichen Ausgangspunkt der Knorpelmineralisation. Typ X Kollagen konnte alliein in der Endzone der sich differenzierenden hypertrophen Chondrozyten in Verbindung mit dem neugebildeten subchondralen Knochen nachgewiesen werden.
\end{abstract}

Schlüsselwörter: Mineralisation, Knorpel, alkalische Phosphatase, Kollagen

\section{Introduction}

Long bone growth in horses continues for up to $5 y$, during which time a number of developmental orthopaedic problems can occur (e.g dyschondroplasia, physitis, angular limb deformities, subchondral cystic lesions, flexural deformities and cuboidal bone malformation) (Mc/lwraith 1986, Jeffcott 1991). These conditions are considered to be disturbances of endochondral ossification i.e. the process of converting hyaline cartilage into bone (Pool 1993). However the pathogenesis of these conditions is poorly understood because there is a paucity of basic information on normal skeletal mineralisation and hypertrophic chondrocyte metabolism in the horse.

The aim of this study was to investigate the histology and ultrastructure of normal growth cartilage in growing horses and to establish whether the enzyme alkaline phosphatase (ALP) or collagen type $X$ are markers for incipient mineralisation in the horse.

\section{Materials and methods}

\section{Animals}

Samples for histological, histochemical, in situ hybridisation and immunolocalisation experiments were collected from 40 horses and ponies ranging in age from 90 days fetus to 12 years. Samples for ultrastructural examination were taken from 3 Thoroughbred foals: one 157 day fetus, one 4 months old and one 18 months old. The animals were humanely destroyed with an overdose of intravenous barbiturate. At postmortem examination all limb joints were examined and found to be free from any gross articular cartilage lesions.

\section{Samples}

Full thickness cartilage samples were harvested from the lateral trochlear ridge of the distal femur. In addition cartilage was harvested from the distal radial growth plate, the proximal humerus, the proximal phalanges and the intermediate ridge of the distal tibia for ALP histochemistry. All samples (except for electron microscopy) were snap frozen and $7 \mu \mathrm{m}$ sections cut on a cryostat.

\section{Histological examination}

Cartilage sections were routinely strained with Haematoxylin and Eosin to demonstrate the normal architecture of the tissues. 
Histochemistry

Sections were fixed in $4 \%$ paraformaldehyde for $20 \mathrm{~min}$ and washed in PBS. ALP activity was detected using a substituted naphthol reaction following the method described by Bancroft (1982). Sections were incubated in $2 \mathrm{mM}$ napthol $\mathrm{AS}-\mathrm{BI}$ phosphate, $4 \mathrm{mM}$ Fast Red in $\mathrm{N}: \mathrm{N}$ dimethylformamide in $0.1 \mathrm{M}$ Tris buffer $(\mathrm{pH} 8.1)$ for $5 \mathrm{~min}$ at $37^{\circ} \mathrm{C}$. As controls, sections were treated with $4 \mathrm{mM}$ levamisole in $0.1 \mathrm{M}$ Tris buffer $(\mathrm{pH} 8.1)$, washed and reacted as above.

\section{Immunolocalisation}

Sections were fixed in $4 \%$ paraformaldehyde for $20 \mathrm{~min}$ and washed in PBS. Immunolocalisation was performed using a monoclonal anti chick type $X$ collagen antibody (diluted 1:100) and indirect immunolocalisation as described by Davies et al. (1991). Controls were performed in which the primary antiserum was replaced with an irrelevant monoclonal antibody.

\section{In situ hybridisation}

Type $X$ mRNA was detected using a cDNA clone ( $p E R X)$ corresponding to a 328bp fragment of the C-terminus of human type $X$ collagen (Reichenberger et al. 1991). In situ hybridisation was performed with 35-S labelled riboporobes as described by Wilkinson (1992) and visualised with autoradiography.

\section{Electron microscopy}

Cartilage was fixed in 1\% gluteraldehyde, 3\% formaldehyde, $5 \%$ polyvinylpyrrolidone and $2 \mathrm{mM}$ calcium chloride in 0.1M PIPES buffer ( $\mathrm{pH} 7.4)$. ALP activity was demonstrated using the method described by Lewis and Knight (1992), using lead citrate as the capturing agent.

\section{Results}

\section{Histological examination}

Equine growth cartilage was shown to consist of three layers of chondrocytes; resting, proliferative and hypertrophic. The depth of each zone depended on the age of the animal; in young animals $(<4 \mathrm{~m})$ the proliferative zone occupied two-thirds of the cartilage. This zone gradually decreased in size with increasing age.

\section{Histochemistry}

ALP activity appeared as a red-pink precipitate apparently restricted to chondrocytes within the hypertrophic zone. Preincubation with levamisole abolished this staining. ALP activity was revealed at the 3 sites in which mineralisation was taking place; in the articular/epiphyseal complex and at either edge of the metaphyseal growth plate. The number of ALP positive cells was related to the age of the animal and the anatomical site studied. Activity was high in animals $<6$ months of age and declined thereafter. After growth plate closure, ALP activity was restricted to a zone approximately 1 cell deep adjacent to the calcification front. Statistically significant differences between sites were found in both age groups $(P<0.001$ in animals $<6$ months of age, and $P<0.005$ in animals $>6$ months of age). In all ages studied ALP activity was highest in the metaphyseal growth plate of the distal radius and lowest in the proximal phalanges.

Type $X$ collagen immunolocalisation and in situ hybridisation

Type $X$ collagen and mRNA was detected in the hypertrophic zone of cartilage in animals $<1$ y old. Type $X$ collagen was present in the pericellular matrix of terminally differentiated hypertrophic chondrocytes (i.e. those adjacent to the newly-forming subchondral bone), but in a more restricted pattern than mRNA. The depth of chondrocytes positive for type $X$ collagen decreased with age, with a maximum of approximately 10 cells deep in fetal animals. No type $X$ collagen was detected in animals $>1$ year of age.

\section{Electron microscopy}

Electron microscopy demonstrated the changes in chondrocyte appearance during the transition from a resting to a hypertrophic phenotype. Mineralisation of the cartilage was seen to begin with the formation of calcium precipitates centred on matrix vesicles of the mid-hypertrophic chondrocytes and to increase through the late hypertrohic zone. ALP activity was detected as an electrondense precipitate on the outer surface membrane and on microvilli of chondrocytes from the mid-proliferative zone through to the hypertrophic zone. Matrix vesicles were seen to be budding off from the chondrocyte surface and high ALP activity was detected in these organelles. In some sections the matrix vesicles appeared to accumulate in the longitudinal septa of the cartilage before mineralisation.

\section{Discussion}

In this study we have identified the presence of ALP and type $X$ collagen within growth cartilage and demonstrated the ultrastructural changes that occur during mineralisation of this cartilage. Matrix vesicles have been identified in cartilage undergoing mineralisation and have been seen to be associated with the onset of calcium deposition. Type $X$ collagen has been shown to be a good marker of incipient bone formation; it is only detected in association with the terminally differentiated hypertrophic chondrocytes as has been reported in other species (Kielty et al. 1985, Schmid and Lisenmayer 1985, Kwan et al. 1989). The distribution of type $X$ collagen and mRNA indicated post-transcriptional regulation of type $X$ collagen expression. ALP has been shown to be associated with both proliferative and hyertrophic chondrocytes and is therefore a less specific marker for the process of mineralisation (Thyberg and Friberg 1972, Ralphs and Ali 1986). 
Both type $X$ collagen immunoreactivity and ALP activity decline with age, reflecting the decrease in the rate of mineralisation that occurs with increasing age. The exact role of type $X$ collagen in the mineralisation process is unknown. It has been postulated that it may target extracellular matrix for removal (Poole and Pidoux 1989), that it may facilitate the spread of mineral through the extracellular matrix (Morris et al. 1992) and that it may have a role in a calcium channel mechanoreceptor within matrix vesicles (Wu et al. 1992). Whatever the mechanism of its action it appears to be intimately asociated with the onset of mineralisation. Similarly the role of ALP in mineralisation remains unknown despite having been associated with the process since 1923 (Robison 1923). It is likely that the enzyme is critically involved in the generation of an increase in local phosphate concentration in regions undergoing mineralisation, thereby aiding the formation of stable mineral deposits.

The findings described in this study provide baseline data on the process of skeletal mineralisation during long bone growth of young horses. This information should facilitate detailed investigations into the pathogenesis of developmental orthopaedic diseases.

\section{References}

Bancroft, J.D. (1982): In "Theory and practice of histological technique" Eds J.D. Bancroft and A. Stevens. Churchill Livingstone, Edinburgh

Davies, M.E., Horner, A. and Dingle, J.T. (1991): Immunorecognition of chondrocytes in articular chondrocytes activated by synovial interleukin-1. Conn. Tiss. Res. 25 243-249.

Jeffcott, L.B. (1991): Osteochondrosis in the horse - searching for the key to pathogenesis. Equine Vet. J Suppl 16 1-3

Kielty, C.M., Kwan, A.P.L., Holmes, D.F., Schor, S.L. and Grant, M.E. (1985): Type $X$ collagen, a product of hypertrophic chondrocytes. Biochem J. 227 545-549.

Kwan, A.P.L., Dickson, I.R., Freemont, A.J. and Grant, M.E. (1989): Comparative studies of type $X$ collagen expression in normal and rachitic chicken epiphyseal cartilage. J. Call Biol. 1Q2 1849-1886.

Lewis, P.R. and Knight, D.P. (1992): Cytochemical staining methods for electron microscopy. In 'Practical methods in electron microscopy' Vol 14 (Ed A.M. Glauert) Amsterdam: North Holland.

Mcllwraith, C.W. (1986): Developmental Orthopaedic Disease Symposium, American Quarter Horse Symposium, Amarillo, Texas 1-77.
Morris, D.C., Moylan, P.E. and Anderson, H.C. (1992): Immunochemical and immunocytochemical identification of matrix vesicle proteins. Bone Min. 17 209-214.

Pool, R.R. (1993): Difficulties in definition of equine osteochondrosis; differentation of developmental and acquired lesions. Equine Vet. J. Suppl 16 5-12.

Poole, A.R. and Pidoux, I. (1989): Immunoelectron microscopic studies of type $X$ collagen in endochondral ossification. J. Cell Biol. 109 2547-2554.

Ralphs, J.R. and Ali, S.Y. (1986): Histochemical localisaion of alkaline phosphatase in rabbit distal ulnar growth plate. In Cell Mediated calcification and matrix vesicles. (Ed Ali S.Y.) Elselvier, New York.

Reichenberger, E., Aigner, T., von der Mark, K., Stob, H. and Bertling, $W$. (1991): In situ hybridisation studies on the expression of type $X$ collagen in fetal human cartilage. Dev. Biol. 148 562-572.

Robison, R. (1923): The possible significance of hexosephosphoric esters in ossification. Biochem. J. 17 289-295

Schmid, T.M. and Lisenmayer, T.F. (1985): Developmental acquisition of type $X$ collagen in the embryonic chick tibiotarsus. Dev. Biol.107 373-381

Thyberg, J. and Friberg, U. (1972): Electron microscopic enzyme histochemical studies on the cellular genesis of matrix vesicles in the epiphyseal plate. J. Ultrast. Res. 41 43-59.

Wilkinson, D. G. (1992): In situ hybridisation: a practical approach. IRL Press, OUP

Wu, L.N.Y., Genge, B.R. and Wuthier, R.E. (1992): Evidence for specific interaction between matrix vesicles proteins and connective tissue matrix. Bone Min. 17 247-265.
F.M.D. Henson,

L.B. Jeffcott

Department of Clinical Veterinary Medicine

University of Cambridge

Madingley Road

Cambridge

CB3 OES

UK

\section{M.E. Davies}

Strangeways Research Laboratory

Worts Causeway

Cambridge

UK 